\title{
Determination of an Effective Heating Radius in District Heating Systems in terms of Reliability
}

\author{
V.A. Stennikov, E.E. Mednikova, I.V. Postnikov*
}

Melentiev Energy Systems Institute of Siberian Branch of Russian Academy of Sciences, Irkutsk, Russia

\begin{abstract}
The paper presents a method developed to determine an effective heating radius (EHR) in district heating systems (DHSs) in terms of reliable heat supply to consumers. The search for EHR for various heating mains from the considered district heating source in DHS involves identifying heat source operation zones in various city areas. At the same time, apart from the search for EHR, the nodal reliability indices are estimated for each consumer and then used (if necessary) to adjust the obtained EHR. The paper briefly discusses some of the practical research results.
\end{abstract}

Index Terms: district heating system, mathematical modeling, effective heating radius, specific costs of heat production and distribution, reliability analysis, nodal reliability indices, theory of hydraulic circuits.

\section{INTRODUCTION}

The effectiveness of the enhancement and preservation of district heating advantages is provided by optimal planning of the DHS functioning and modernization, which implies the determination of DHS scale, the distance of heat-carrying agent transportation, and the fulfillment of the heat supply quality and reliability requirements in the context of increasing heat demand. The validity of the decisions made on these issues is determined by the heating radius or the heat network length from the heating source to the consumer. In this regard, finding an effective heating radius (EHR) is one of the essential objectives when constructing efficient heating systems. The determination of EHR is also instrumental in designing the efficient 4th generation DHS [1-3].

According to the adopted procedure for preparing and making decisions, this and some other tasks related to the

\footnotetext{
${ }^{*}$ Corresponding V. A. Stennikov.

E-mail: postnikov@isem.irk.ru
}

http://dx.doi.org/10.38028/esr.2021.01.0007

Received March 16, 2021. Revised March 19, 2021.

Accepted March 26, 2021. Available online May 26, 2021.

This is an open access article under a Creative Commons Attribution-NonCommercial 4.0 International License.

(C) 2021 ESI SB RAS and V. A. Stennikovs. All rights reserved. construction of optimal DHS are considered in various stages of the heating system design with varying degrees of their detail (detailed planning of the city, heat supply scheme, etc.). The regulations for accomplishing these tasks are prescribed by dedicated normative and legislation acts that determine their order, sequence, composition, scope, terms, and other conditions [4-8].

The Federal Law "On Heat Supply” [4] is a fundamental regulatory document that establishes the legal framework for economic relations in heat production, transmission, and consumption in DHS. This document defines the basic concepts used in the development of heat supply schemes, including EHR. According to clause 30 of Article 2 of the Law "On Heat Supply", EHR is a maximum distance between the heat-consuming node and the nearest heat source in DHS, which, when exceeded, makes it costineffective to connect the heat-consuming node to this system due to an increase in total costs in the system. Sections 2, 3, and 10 of the Resolution [5] declare the need to calculate the EHR to determine optimal coverage areas for existing, reconstructed and new heat source providing an expected heat load in new city areas.

The recommendations for the development of heat supply schemes are approved by the Order of the Ministry of Energy of the Russian Federation [7]. They define the EHR concept and note the need for its assessment. They also propose a simplified methodology for its calculation, which is aimed at obtaining integral EHR estimates (in contrast to nodal ones) without considering reliability. Thus, the determination of the optimal scale of DHS based on EHR, which is crucial in substantiating the efficiency of heat supply scheme, requires the development of a scientifically grounded methodology.

The analysis of the scientific and technical literature indicates that despite the absence of methods approved by normative documents, the EHR calculation issue has been given much attention since the time of the district heating establishment. The objective of determining the limiting radius of district heating was formulated for the first time in [9], and concepts of "economic" and "limiting" heating radius were pioneered in [10]. Most further studies focusing on the determination of EHR or optimal areas of heat source operation fall on the 1960s-the 1980s 
[11-14] since this was the period that saw the most intensive growth in both the number and the scale of DHS. The findings obtained suggest that the optimal EHR and the area of heat source operation depend significantly on the structure and parameters of the considered system. Recently, the research has been resumed to determine the effective zones of district heating [15-17]. The proposed methods are instrumental for aggregate solutions for the DHS development strategy. At the same time, they aim to determine a single EHR value for the system under the assumption that heat loads are evenly distributed. This assumption, however, is very rarely consistent with actual systems and cannot be applied to most operating heating systems. Also, the considered methods used to assess EHR do not consider reliability requirements, which in practice can lead to frequent disconnections of consumers located in the EHR zone.

\section{Methodology}

The main idea of the proposed methodological approach to determining EHR is that for each district heat source, one should calculate EHR for each direction of the main transmission pipelines of the heat network connected to this source. At the same time, consumers in the EHR zone should be provided with the required (normative) level of heat supply reliability.

The method designed to determine EHR relies on the following assumptions and propositions:

1. The areas of prospective and existing housing development are determined following the general plan of the city and applications for technical connection of heat load;
2. The criterion that limits EHR for heat source, and beyond which the connection of new consumers leads to an increase in the specific costs for the considered DHS, is the cost of heat production and transportation;

3. The EHR boundary is calculated for each transmission pipeline from heat source, given the technical and economic parameters of the heat source and heat network, climatic conditions, and other properties and features of the studied system;

4. The EHR is limited by network nodes, at which the heat prime cost (nodal prime cost) exceeds the average cost for DHS;

5. The optimal distance of the heat carrier transport along each transmission pipeline of heat network from a heat source to the most distant consumer node is determined according to the calculated EHR value.

The proposed method for determining the EHR for DHS with regard to reliability requirements consists of the following main stages.

1. Build an information base for district heating zones, including territorial planning; consumer loads; locations; technical and economic indices of heat source; length, parameters of existing heat network sections and new ones.

2. Calculate the connected heat load for each district heat source:

$$
Q_{i}=\sum_{j \in J(i)} Q_{j}+Q_{\text {loss }}, i \in I
$$

where $i$ and $j$ are the number of heat sources and the number of consumers, respectively; $I$ is a set of heat sources; $J(i)$ is a subset of consumers connected to the $i$-th source ( $J$ is a total set of consumers); $Q_{j}$ is heat

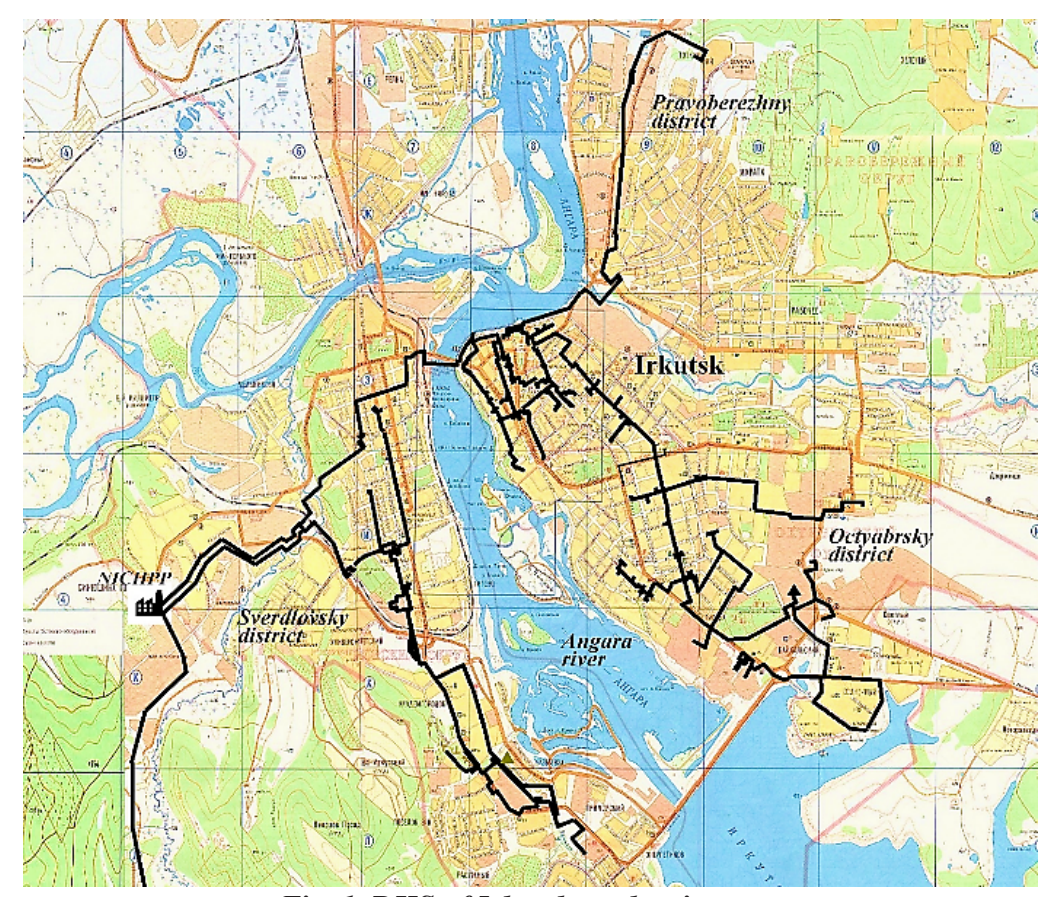

Fig. 1. DHS of Irkutsk on the city map. 
load of the $j$-th consumer connected to the considered source, MW; $Q_{\text {loss }}$ is heat losses in the system, MW. Expression (1) is used to formulate the total heat balance in the considered DHS given all heat sources and consumers:

$$
Q_{i}=\sum_{j \in J} Q_{j}+Q_{\text {loss }}
$$

Each EHR solution obtained subsequently must satisfy this condition.

3. Determine the length of transmission pipeline for each heat source based on the calculated scheme of the system at issue and the main characteristics of the heat network sections (diameters, lengths, actual heat carrier flow rate).

4. Calculate thermal and hydraulic conditions in the heat network using the methods of the theory of hydraulic circuits (THS) [18], according to which the heat carrier flow distribution in the network is described by the following system of equations in matrix form:

$$
\begin{aligned}
& \mathbf{A x}=\mathbf{G}, \\
& \overline{\mathrm{A}}^{\mathrm{T}} \mathbf{p}=\mathbf{h}-\mathbf{H}, \\
& \mathbf{h}=\mathbf{S X x},
\end{aligned}
$$

where $\mathbf{A}$ is a matrix of connections of linearly independent nodes and sections of the network; $\mathbf{x}$ is a vector of heat flow rates in the network sections, $\mathrm{t} / \mathrm{h} ; \mathbf{G}$ is a vector of flow rates at nodes, $\mathrm{t} / \mathrm{h} ; \overline{\mathrm{A}}^{\mathrm{T}}$ is a transposed matrix of connections of nodes and branches in the scheme; $\mathbf{p}$ is a vector of pressures at nodes, $\mathrm{mWC} ; \mathbf{h}, \mathbf{H}$ are vectors of losses and operating heads, $\mathrm{mWC} ; \mathbf{S}$ is a diagonal matrix of hydraulic resistances, $\mathrm{mh}^{2} / \mathrm{t}^{2} ; \mathbf{X}$ is a diagonal matrix of absolute values of flows on network sections, $\mathrm{t} / \mathrm{h}$.

5. Test if there is an available capacity of the existing district heat source, given the maximum heat load of the $i$-th source $-Q_{i}^{\max }, \mathrm{MW}$.

Based on the test results, the following conclusions are made:

a) in the case of available capacity in the operation area of the considered source $\left(Q_{i}>Q_{i}^{\max }\right)$, additional capital investments are not required to connect consumers;

b) in the case of no available capacity in the operation area of the considered source $\left(Q_{i} \leq Q_{i}^{\max }\right)$, it is necessary to expand the source capacity and assess the corresponding investment.

6. Calculate annual specific costs for the heat production and transportation (prime cost) in DHS from the considered $i$-th heat source [14]:

$$
\begin{gathered}
Z_{i}=c_{i}^{h}+\alpha k_{i}+(f+\alpha) \frac{1}{Q_{i}} \sum_{n \in N(i)}\left(k_{n} d_{n} l_{n}\right)+ \\
+c_{e} \tau_{p} \frac{1}{367 \eta Q_{i}} \sum_{n \in N(i)}\left(\psi_{n} x_{n} l_{n}\right),
\end{gathered}
$$

where $n$ is the number of the heat network section; $N(i)$ is a subset of network sections that belong to the heat load area from the $i$-th heat source ( $N$ is a full set of network sections); $c_{i}^{h}$ is a heat production prime cost at the $i$-th heat source, RUB/MWh; $\alpha$ is a discounting coefficient; $k_{i}$ is the specific investment in capacity expansion of the $i$-th source, $\mathrm{RUB} /(\mathrm{MW}) ; f$ is a share of deductions from capital costs for the heat network depreciation, repairs and maintenance; $k_{n}$ is the specific investment in the construction of the $n$-th network section, RUB/m; $d_{n}$ is diameter of the $n$-th network section, $\mathrm{m} ; l_{n}$ is length of the $n$-th network section, $\mathrm{m} ; c_{e}$ is electricity cost, RUB/kWh; $\tau_{p}$ is the number of operating hours of the pumping unit with the design load, $h ; \eta$ is the efficiency of the pumping unit; $\psi_{n}$ is specific pressure drop in the $n$-th network section, $\mathrm{mWC} / \mathrm{m}$.

7. Calculate the specific costs for heat production and transportation (prime cost) for each node along each transmission pipeline from the $i$-th heat source:

$$
\begin{aligned}
Z_{m}= & c_{i}^{h}+\alpha k_{i}+(f+\alpha) \frac{1}{Q_{i}^{m}} \sum_{n \in N(m)}\left(k_{n} d_{n} l_{n}\right)+ \\
& +c_{e} \tau_{p} \frac{1}{367 \eta Q_{i}^{m}} \sum_{n \in N(m)}\left(\psi_{n} x_{n} l_{n}\right),
\end{aligned}
$$

where $m$ is the number of the network node ( $m \in M$, where $M$ is a set of nodes); $N(m)$ is a subset of network sections connecting nodes that belong to the transmission pipeline from the $i$-th heat source; $Q_{i}^{m}$ is heat load at node $m$ that belongs to the transmission pipeline from the $i$-th heat source, MW.

8. Assess a system-average level of specific annual costs for heat production and transportation:

$$
\bar{Z}=\left(1 / \sum_{i \in I} Q_{i}\right) \sum_{i \in I} Q_{i} Z_{i} .
$$

9. Determine the EHR boundaries for each transmission pipeline, i.e., a subset of nodes, for which the heat production cost does not exceed its system-average level. A node's belonging to the EHR zone is formalized according to the condition:

$$
\begin{aligned}
& m \notin M_{e f f}, \text { if } Z_{m} \geq \bar{Z}, \\
& m \in M_{e f f}, \text { if } Z_{m}<\bar{Z}
\end{aligned}
$$

where $M_{\text {eff }}$ is a subset of network nodes located within the EHR zone.

10. Determine two main reliability indices (RI) [16], i.e., the availability factor (AF) and the failure-free operation probability (FOP). These indices can be calculated for each node $\mathrm{m}$ of the calculated scheme using the methodology for heating system reliability assessment presented in [19], according to the following formulas:

$$
\begin{aligned}
& K_{m}=\sum_{s \in E} p_{s}\left[\left(\tau_{0}-\tau_{s m}\right) / \tau_{0}\right], \\
& R_{m}=\exp \left(-p_{0} \sum_{s \in E} \sum_{n \in N_{s}} \tau_{s m} \lambda_{n}\right),
\end{aligned}
$$

where $K_{m}$ and $R_{m}$ are nodal AF and FOP, respwectively; $s$ is the number of the system state; $E$ is a set of system states; $p_{s}$ is probability of state $s ; \tau_{0}$ is the calculated time, $\mathrm{h} ; \tau_{s m}$ is part of the calculated time, during which state $s$ is a failure state for node $m ; p_{0}$ is the probability of a fully 
without taking into account reliability

$\square$ with taking into account reliability

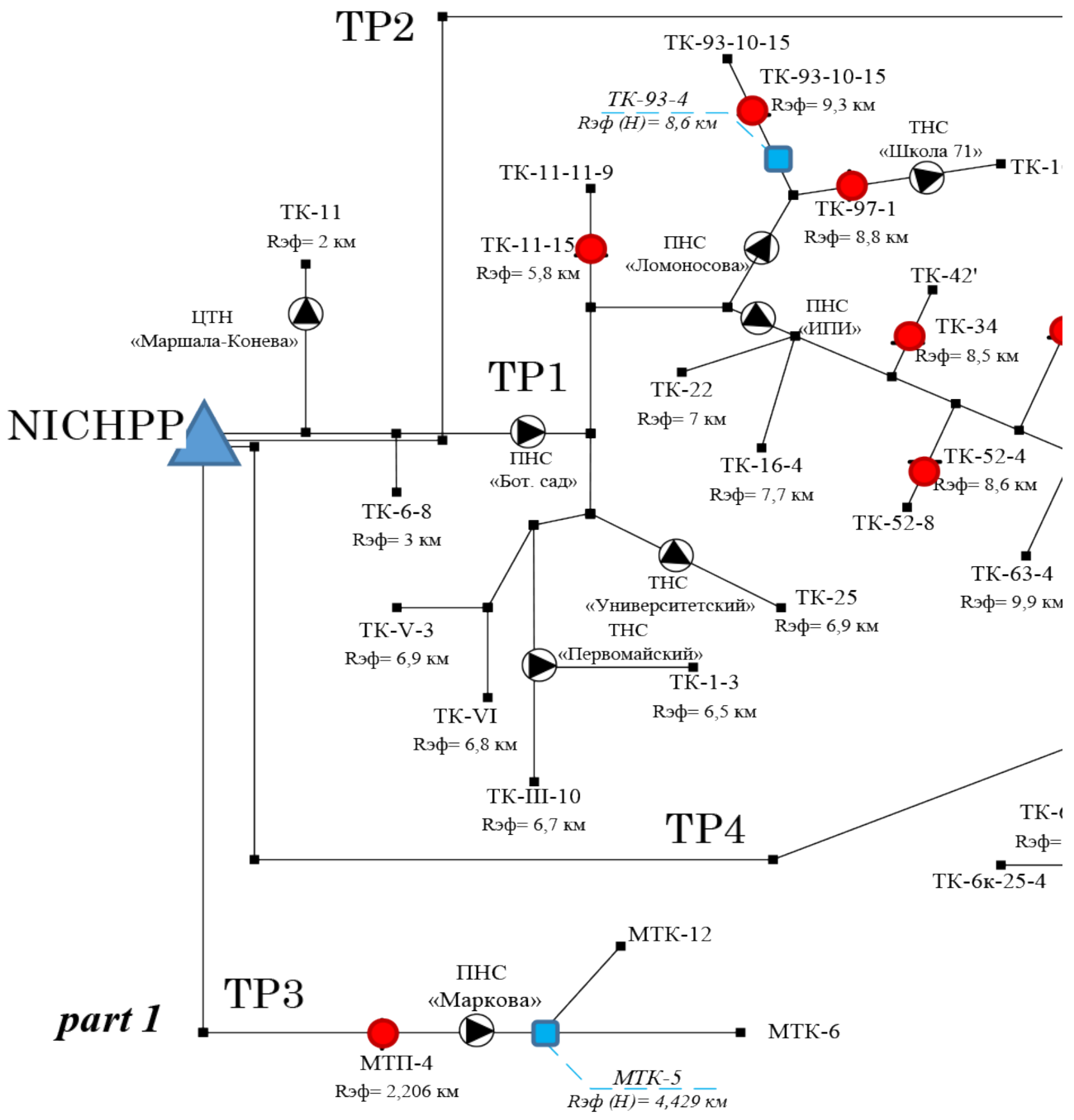

Fig. 2. Aggregate scheme of DHS with EHR solutions. 


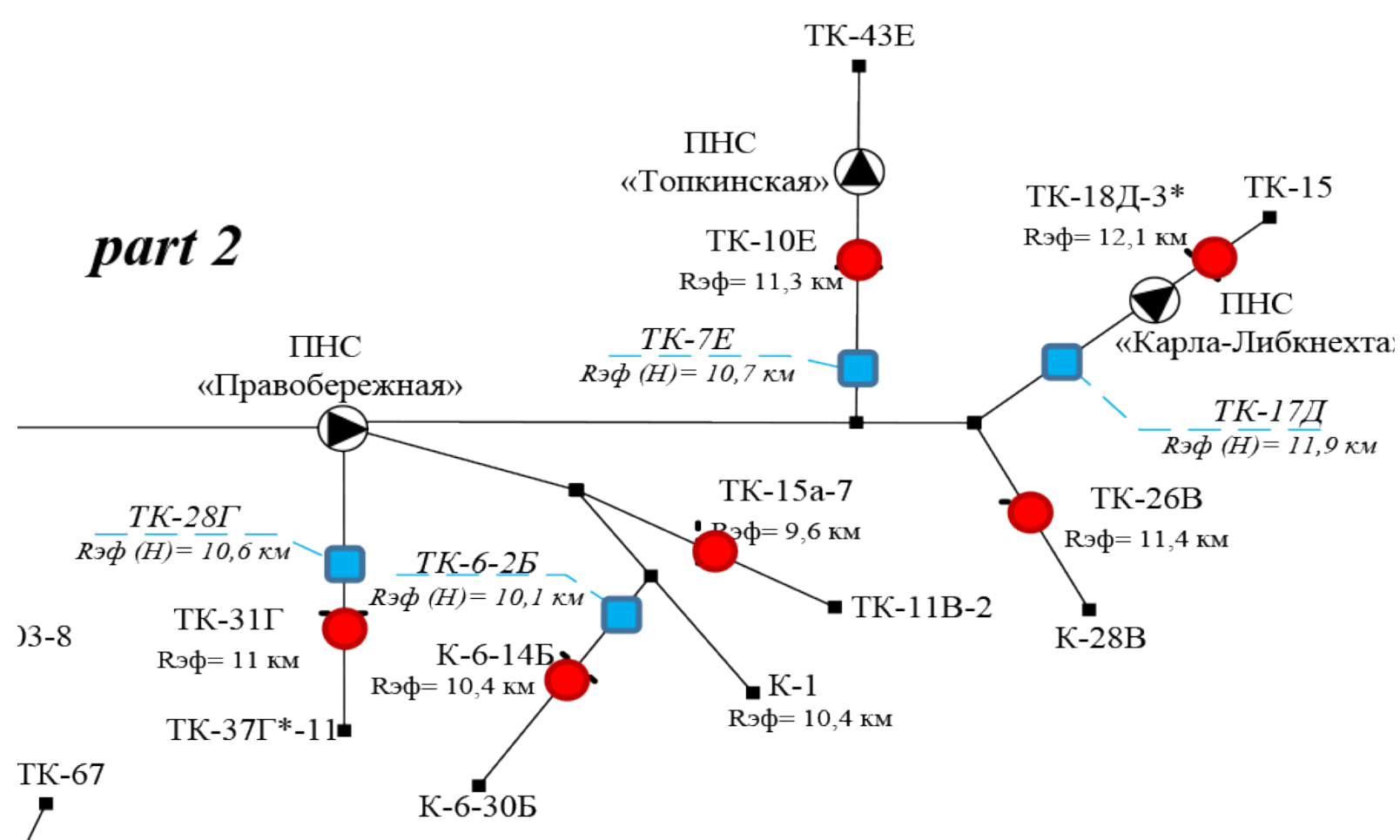

$\mathrm{TK}-42 *$

$\mathrm{R} э \phi=9,8 \mathrm{KM}$
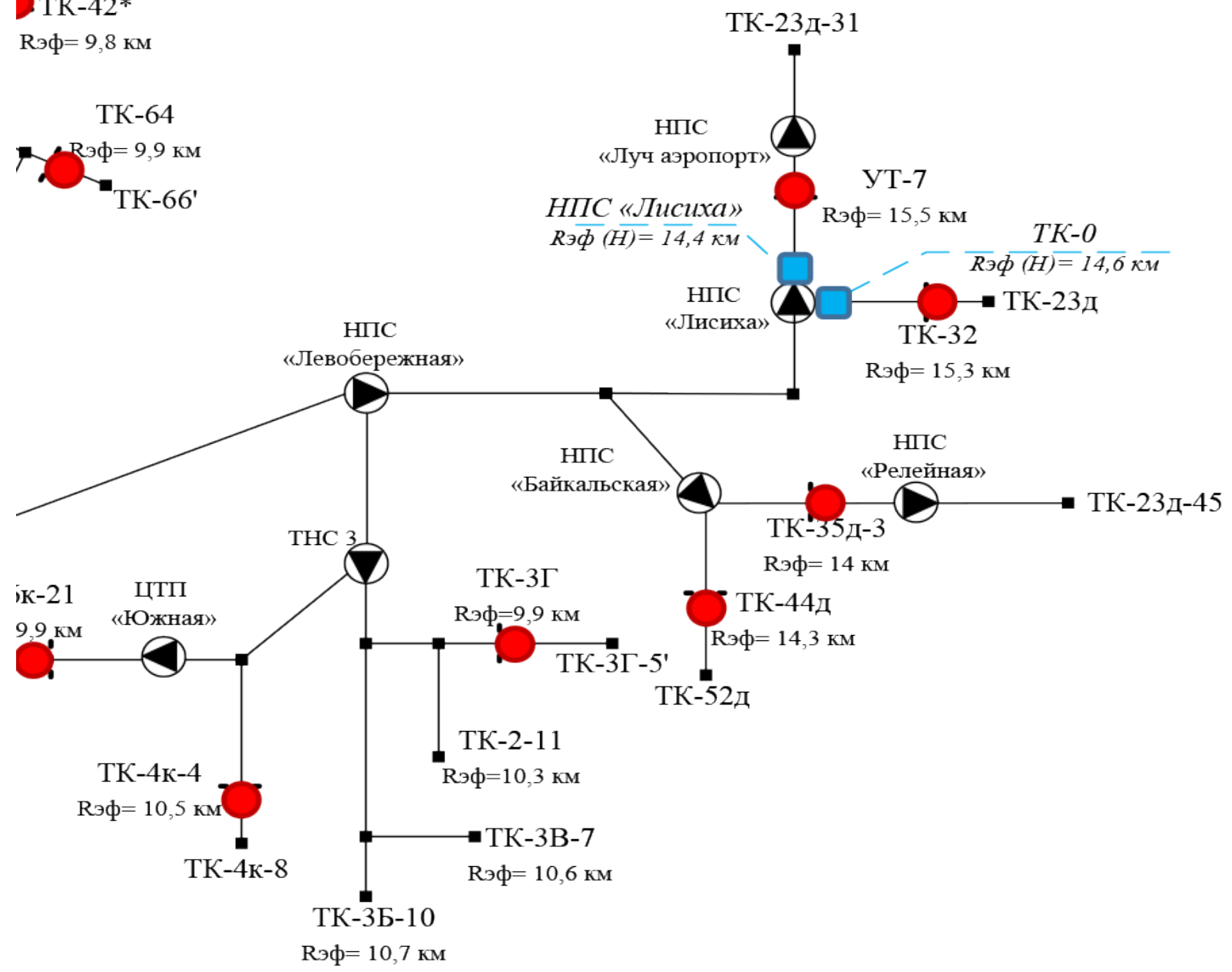

Fig. 2. Aggregate scheme of DHS with EHR solutions. 
operational system state $(s=0) ; N_{s}$ is a subset of the system components (sections of the heating network), the failure of which corresponds to the transition to the state $s ; \lambda_{n}$ is a failure rate of component $n, 1 / \mathrm{h}$.

The probabilities of states $p_{s}$ are determined by solving a system of equations that describe a stationary markov random process of the evolution of events in the system, i.e., failures and restorations of its components (network sections) $[19,20]$ :

$$
\sum_{n \in N_{s}}\left(\lambda_{n}+\mu_{n}\right)=\sum_{z \in E_{s}} p_{z} \sum_{n \in N_{z}}\left(\lambda_{n}+\mu_{n}\right), s \in E
$$

where $z$ is the number of system state (introduced to formulate the defined system of equations); $E_{s}$ is a subset of states from which a transition to state $s$ is possible; $p_{z}$ is the probability of state $z$ of the system; $N_{z}$ is a subset of components whose failure or recovery corresponds to a transition from state $z$ to state $s ; \mu_{n}$ is a recovery rate of component $n, 1 / \mathrm{h}$. Values $\tau_{s m}$ are determined using the Rossander equation [14, 21], which is also used to set the heat load at any time during the calculated period or the socalled heat load duration curve. The calculations employ the levels of heat supply in various system states, which are determined from the assessment of consequences of post-emergency thermal-hydraulic conditions in the heat network based on the system of equations (3)-(5). To this end, multivariate calculations of the flow distribution in the network are carried out for a failure condition of its various sections. In doing so, one takes into account the time reserve due to the heat storage effect. Methods and models for analyzing the DHS reliability, as well as their practical application, are discussed in detail in [19, 20, 22-25].

11. Verify EHR solutions for fulfillment of heat supply reliability requirements in terms of the standard values of the nodal reliability indices used. Thus, for each node belonging to the EHR zone, the following conditions must be met:

$$
K_{m} \geq K_{0}, m \in M_{e f f},
$$

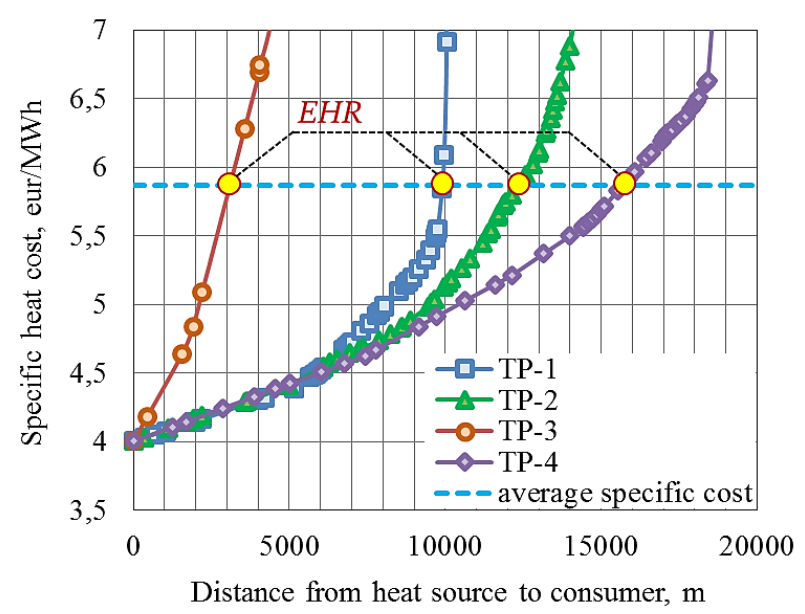

Fig. 3. Specific heat cost for the longest branches of the considered DHS transmission pipelines: the points of crossing the average level line (dashed line) correspond to EHR solutions

$$
R_{m} \geq R_{0}, m \in M_{\text {eff }},
$$

where $K_{0}$ and $R_{0}$ are standard values of AF and FOP, respectively. The methods for assessing the heating system reliability [19] usually rely on the AF to estimate the design level of heating, and FOP to estimate the reduced reliability level. In this case, the reliability criterion is the minimum permissible temperature of the internal air at the node under consideration, which is determined by the level of heat supply.

If conditions (14) and (15) are not met, the EHR zone is limited to the node, which is most distant from the heat source and at which the reliability requirements are satisfied, with the EHR zone reduced. If the EHR zone cannot be reduced (for example, if there are no other sources, to which consumers beyond the boundaries of this zone can be connected according to reliability conditions), then measures are developed to increase reliability, which involves designing redundant pipelines and assessing the necessary volume of re-laying the dilapidated and emergency heat network sections. After that, we return to point 3 of the method. At the same time, calculation of specific annual heat transportation costs should take into account additional capital investments in measures to improve reliability.

The obtained EHR solutions must be annually updated according to the growing heat loads. Normally, the connection of new consumers in the case of available heat source capacity and the throughput of pipelines leads to an increase in operating costs, which must be compensated for by the consumer that has an individual heat tariff set. The effectiveness of connecting a new consumer to the existing heat network within the EHR is assessed based on an additional criterion, the so-called local EHR, which allows estimating the economically feasible distance between the consumer and the point of connection to the system $[26,27]$.

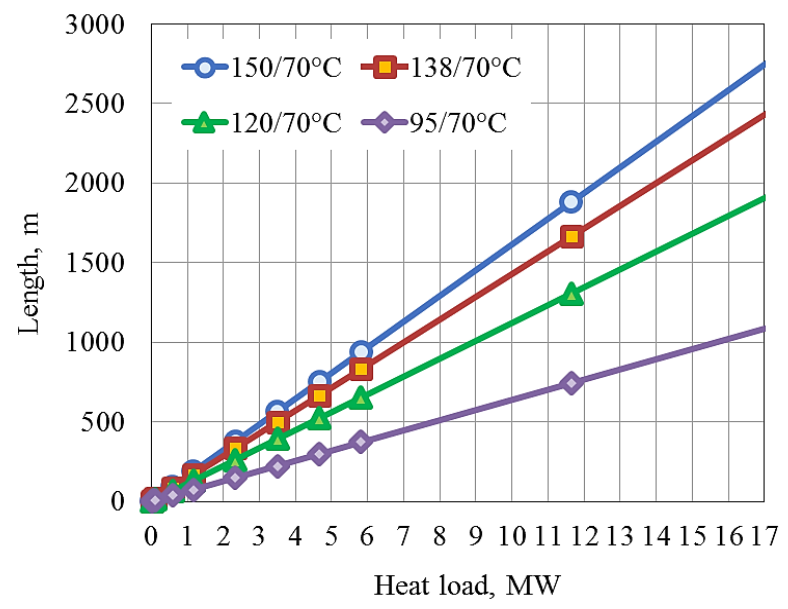

Fig. 4. The maximum length of a heat pipeline from the point of new consumer connection to transmission pipeline of DHS in question 


\section{CASE STUDY}

The presented methodology was used to calculate EHR for the DHS of the city of Irkutsk. The heat producer for the DHS is the Novo-Irkutskaya CHP (NICHP). Its installed heat capacity is $2010 \mathrm{MW}$ and the installed electric capacity is $708 \mathrm{MW}$. The general scheme of the considered DHS is shown on the city map in Fig. 1. The supply-return temperature of heat supply is $150 / 70^{\circ} \mathrm{C}$. Transmission and distribution pipelines of the heat network have a two-pipe design. There are heat network pipelines laid both above ground and underground (mainly in non-passable channels). The total heat network length from NICHP is $474 \mathrm{~km}$, including about $113 \mathrm{~km}$ of transmission pipeline. The NICHP supplies heat partially or fully to three urban districts through three transmission pipelines (TP) - TP1, TP2, and TP4 (Fig. 2). TP3 is used to supply heat to consumers of a detached suburban village (Fig. 2).

The calculated scheme of the considered DHS with EHR solutions is shown in Fig. 2. It shows the EHR boundaries for four transmission pipelines from the NICHP. These boundaries were calculated both with and without reliability factored in, i.e., after adjusting the boundaries according to the nodal reliability requirements.

The required nodal reliability indices are set according to the standards presented in [19] and are 0.979 and 0.905 for AF and FOP respectively. The EHR values obtained disregarding reliability vary from $2 \mathrm{~km}$ to $15.5 \mathrm{~km}$. The net heat cost for consumers located outside the allocated EHR zones exceeds the system-average value, and their connection seems to be economically unfeasible.

The analysis of the system reliability indicates that the requirements for the nodal reliability indices for some nodes within the EHR boundaries are not met. Therefore, the EHR boundaries are adjusted according to the specified requirements for the nodal reliability indices. Thus, to meet the reliability requirements, the maximum EHR value was decreased from $15.5 \mathrm{~km}$ to $14.6 \mathrm{~km}$, and the length of heating mains in the EHR zone was reduced by $4.2 \mathrm{~km}$ and made up $67.7 \mathrm{~km}$. From the reliability perspective, the EHR zone covers $284.3 \mathrm{~km}$ of pipelines out of the total $474.3 \mathrm{~km}$, while about $40 \%$ of the heat network is located outside the EHR zone.

Figure 3 indicates the specific costs of heat supply for the most extended transmission pipeline of heat network in comparison with their system-average level. The relationship between the heat load and the material characteristic of the heat network has the main effect on the specific heat supply costs $[26,27]$. The higher the specific material characteristic, the higher the specific costs, and vice versa.

Figure 4 shows the results of an assessment of the maximum allowable pipeline length from the point of new consumer connection to the existing heat network pipeline located in the EHR zone (assessment of the local EHR). The calculation was carried out for different consumer heat loads under various temperature conditions in the network. The Figure indicates, for example, that the connection of a new consumer is cost-effective if the pipeline is constructed assuming $1000 \mathrm{~m}$ for $6 \mathrm{MW}$ at a temperature profile of $150^{\circ} / 70^{\circ} \mathrm{C}$. A smaller difference between the temperatures in supply and return pipelines is characterized by an increase in capital and operating costs, which leads to a decrease in the maximum length of the network section for connecting new consumers. Heat supply to consumers outside the EHR zone, as a rule, requires the construction of a new heat source. At the same time, we can determine possible boundaries for expanding the EHR zone (i.e., the connection of new consumers outside the EHR zone) by using some additional indices that take into account various factors, such as uneven heat load distribution, the possibility of compensating for excess operating costs at the expense of the consumer, additional measures to ensure the heat supply reliability, and others.

\section{CONCLUSION}

The paper proposes a method for determining optimal district heating zones based on the effective heating radius criterion, which is understood as a set of nodes of the system studied, at which heat production and transportation costs do not exceed its system-average value. The methodology provides the requirements for the heat supply reliability assessed using nodal reliability indices that allow pinpointing the most unreliable nodes in the heat network. The developed method is universal and can be applied to district heating systems of any structure and scale, given their characteristics.

Practical calculations show that the methodological approach to effective heating radius calculation for the network nodes for each heating main from the heat source provides the most informed and detailed effectiveness estimates of heating to consumers. At the same time, the substantiation of the connection of new consumers within the effective heating radius boundaries requires dedicated assessments using an additional criterion, i.e., the local effective heating radius. Some additional indices are also needed to determine possible boundaries for the effective heating radius zone expansion.

The proposed method for determining the effective heating radius in district heating systems can be recommended for designing urban heat supply schemes. The case study of effective heating radius estimation for Irkutsk district heating system has confirmed the effectiveness of the methodology and demonstrated the reliability of solutions obtained.

\section{ACKNOWLEDGMENT}

The research was carried out under State Assignment Project (no. FWEU-2021-0002) of the Fundamental Research Program of the Russian Federation 2021-2030. 


\section{REFERENCES}

[1] H. Lund, S. Werner, R. Wiltshire, et al, "4th Generation District Heating (4GDH): Integrating smart thermal grids into future sustainable energy systems," Energy, 2014, vol. 68, pp. 1-11.

[2] H. Lund, N. Duic, P. Østergaard, B. Mathiesen, "Smart energy systems and 4th generation district heating," Energy, 2016, vol. 110, pp. 1-4.

[3] H. Lund, P. Østergaard, M. Chang, et al, "The status of 4th generation district heating: Research and results," Energy, 2018, vol. 164, pp. 147-159.

[4] Federal Law of 27.07.2010 No. 190-FZ (as amended on 29.12.2014) "On Heat Supply".

[5] Decree of the Government of the Russian Federation of 22.02.2012 No. 154 (as amended on 07.10.2014) "On the requirements for heat supply schemes, the procedure for their development and approval".

[6] Decree of the Government of the Russian Federation dated 04.16.2012 No. 307 "On the procedure for connecting to heat supply systems and on amending some acts of the Government of the Russian Federation"

[7] Order of the Ministry of Energy of Russia No. 212 of 03.05.2019 "On approval of guidelines for the development of heat supply schemes".

[8] Decree of the Government of the Russian Federation of October 22, 2012 No. 1075 (as amended on January $24,2017)$ "On pricing in the field of heat supply."

[9] L.K. Yakimov, "Limit radius of action of district heating," Heat and Power, 1931, vol. 9, pp. 8-10.

[10] V.V. Dmitriev, The main issues of the district heating development in cities. Leningrad: GONTI, 1933.

[11] V.Ya. Khasilev, "Issues of technical and economic calculation of heating networks," in Design of urban heating networks. Gosenergoizdat, 1957.

[12] E.P. Shubin, "Enlarged technical and economic indices for urban heat networks," in Designing urban heat networks. Gosenergoizdat, 1957.

[13] L.S. Khrilev, I.A. Smirnov, Optimization of district heating and district heating systems. Moscow: Energy, 1978.

[14] E.V. Sennova, V.G. Sidler, Mathematical modeling and optimization of developing heat supply systems. Novosibirsk: Science, 1987.

[15] V.G. Semenov, R.N. Razorenov, "Express analysis of the relationship between the heat transport efficiency and the remoteness of consumers," Heat Supply News, 2006, no. 6, pp. 36-38.

[16] V.N. Papushkin, "Heat supply radius. Well forgotten old swarm," Heat Supply News, 2010, no. 9, p. 44-49.

[17] N.D. Chichirova, I.G. Akhmetova, "Assessment of the effective radius of the district heating systems of the city of Kazan," Academenergo Proceedings, 2016, No. 1, pp. 89-95.

[18] A.P. Merenkov, V.Ya. Khasilev, Theory of hydraulic circuits. Moscow: Nauka, 1985.
[19] E.V. Sennova, A.V. Smirnov, A.A. Ionin, et al, Reliability of heat supply systems. Novosibirsk: Science, 2000.

[20] V.A. Stennikov, I.V. Postnikov, "Comprehensive analysis of the reliability of heat supply to consumers," Izv. RAS. Energy, 2011, No. 2, pp. 107-121.

[21] E.G. Sklovskaya et al, "Mathematical description of heat load duration curves for calculating technical and economic indices of heating systems," Bulletin of Universities. Energy, 1982, No. 1, pp. 75-77.

[22] V.A. Stennikov, I.V. Postnikov, "Methods for the integrated reliability analysis of heat supply," Power Technology and Engineering, 2014, vol. 47(6), pp. 446-453.

[23] V.A. Stennikov, I.V. Postnikov, "Methodological support for a comprehensive analysis of fuel and heat supply reliability," in "Sustaining power resources through energy optimization and engineering» (ed. by Vasant P. and Voropai N.I.). Hershey PA: Engineering Science Reference, IGI Global, 2016.

[24] I. Postnikov, V. Stennikov, E. Mednikova, A. Penkovskii, "Methodology for optimization of component reliability of heat supply systems," Applied Energy, 2018, vol. 227, pp. 365-374.

[25] I. Postnikov, V. Stennikov, "Modifications of probabilistic models of states evolution for reliability analysis of district heating systems," Energy Reports, 2020, vol. 6, pp. 293-298.

[26] V. Stennikov, E. Yakimets, "Optimal planning of heat supply systems in urban areas," Energy, 2016, vol. 110, pp. 157-165.

[27] V. Stennikov, E. Mednikova, I. Postnikov, A. Penkovskii, "Optimization of the effective heat supply radius for the district heating systems," Environmental and Climate Technologies, 2019, vol. 23(2), pp. 207-221.

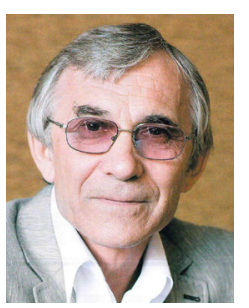

Valery Stennikov, Corresponding Member of RAS, Professor, Director of Melentiev Energy Systems Institute of Siberian Branch of the Russian Academy of Sciences (ESI SB RAS), Irkutsk, Russia. Valery Stennikov is author and co-author of more than 400 scientific publications. His research interests are systems research in the energy sector, theory of hydraulic circuits, mathematical modeling, optimization methods, heat supply systems, district heating systems, cogeneration, reliability, energy efficiency, energy saving, intelligent energy systems. 


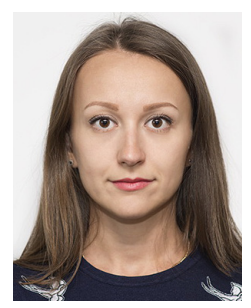

Ekaterina Mednikova, Researcher at the Laboratory of Heat Supply Systems of Melentiev Energy Systems Institute of Siberian Branch of the Russian Academy of Sciences (ESI SB RAS), Irkutsk, Russia. She is author and co-author of more than 40 scientific publications. Her research interests are energy systems, district heating, individual heating, territory zoning by type of heat supply, CHP, mathematical modeling, optimization, energy efficiency.

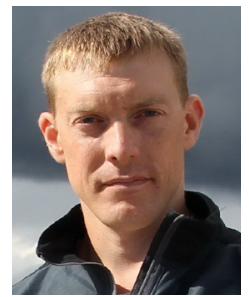

Ivan Postnikov, Ph.D., Senior Researcher in the Laboratory of Heat Supply Systems of Melentiev Energy Systems Institute of Siberian Branch of the Russian Academy of Sciences (ESI SB RAS), Irkutsk, Russia. Ivan Postnikov is author and co-author of more than 100 scientific publications. His research interests are energy systems, district heating systems, CHP, mathematical modeling, reliability, random processes, optimization, energy efficiency, intelligent energy systems, prosumer, renewable energy. 